\title{
HACIA UNA TEORÍA DEL SIGNO ESPACIAL EN LA FICCIÓN NARRATIVA CONTEMPORÁNEA
}

\author{
Natalia Álvarez Méndez
}

Universidad de León

\section{INTRODUCCIÓN AL SIGNO ESPACIAL EN EL GÉNERO NARRATIVO}

Al contemplar el panorama bibliográfico de la Teoría de la Literatura, es bastante habitual advertir la existencia de múltiples estudios relativos a la teoría de la ficción, los acontecimientos, el tiempo o los tipos de personaje, de narrador y de discursos narrativos. En comparación, apenas se accede a ideas relativas al espacio, a su significado o a sus funciones dentro de los textos de prosa ficcional. No se ha negado en ningún momento que se trata de un elemento esencial de las tramas ${ }^{1}$ (Bal, 1985;

1 A pesar de la complejidad y ambigüedad que conlleva el espacio literario, todos los críticos han estado siempre de acuerdo en que constituye uno de los elementos imprescindibles para organizar las creaciones de los mundos ficcionales. 
Albadalejo, 1992; Garrido Domínguez, 1993), pero tampoco se ha mostrado de manera sistemática su gran importancia y riqueza textual. Algunos motivos que han propiciado esta situación actual proceden ya de la tradición teórica. Así pues, además de haberle dedicado al espacio una atención excesivamente menor en comparación con otras cuestiones narratológicas, ha influido también negativamente la falaz creencia de la prioridad del tiempo sobre el espacio; idea errónea (Gullón, 1974: 248; Bajtín, 1982: 220; Zoran, 1984: 310) derivada de la mayor sistematización que ha acompañado al estudio teórico del primero y que no puede sostenerse de forma taxativa ${ }^{2}$.

Para poder realizar un análisis íntegro de la dimensión espacial en la narrativa y una justificación pormenorizada de la posición privilegiada que este elemento sustenta en la ficción en prosa, es necesario acercarse a aspectos tan relevantes como el de su noción y su lugar en la ficción; su origen y desarrollo; sus funciones; su presentación; su percepción; así como el de las diversas tipologías y maneras de construir la experiencia espacial ${ }^{3}$. Al analizar estos aspectos teóricos, se aprecia que la mayor parte de las investigaciones existentes en torno al espacio novelesco se reducen a la aplicación a obras concretas de aspectos aislados. Sin embargo, a pesar de las lagunas propias de muchos análisis y de la falta de sistematización que caracteriza al estudio de este elemento, sí existen sugestivas aportaciones que no se deben olvidar. En esta línea sobresale, en primer lugar, el sentido ontológico asociado al espacio literario, con la concepción tradicional, procedente de Aristóteles, de un marco o lugar físico en el que se desarrolla la acción, un ámbito topográfico de la historia narrada en el que se sitúan los personajes.

Muchas ideas actuales ponen de relieve, por el contrario, la convicción de que este componente de la trama no puede definirse de mane-

2 Existen estudiosos como Hamburger (1957) que sostienen el carácter preeminente del tiempo sobre el espacio, pero en la actualidad se constata que no hay supremacía de una coordenada $u$ otra, sino una intensa interdependencia. Así lo declara Estébanez Calderón (1999: 361) en sus estudios: «Según Kant, todas las intuiciones de espacio son también intuiciones en el tiempo. En el pensamiento contemporáneo algunos investigadores han afirmado la total interdependencia de ambas categorías, de forma que "no hay espacio sin tiempo ni tiempo sin espacio" (S. Alexander, 1927). Nuestra mente, al evocar en el recuerdo acontecimientos, objetos y personas, los sitúa en un espacio y en un tiempo determinados: en ese contexto espacio-temporal son revividos en nuestra conciencia.»

3 Aspectos analizados con minuciosidad por mí en el estudio Espacios narrativos (Álvarez Méndez, e.p.), que amplía y detalla las cuestiones teóricas esbozadas en el presente artículo. 
ra tan simple. Esto se debe a estudios previos como los de Leibniz, Kant o Hegel (Valles Calatrava, 1994: 150), que comienzan a demostrar la vinculación de espacio y tiempo, conduciendo la teoría de la literatura hacia la noción de cronotopo de Bajtín (1975: 237-409), en la que se explicita la conexión de relaciones temporales y espaciales conformadas en un todo concreto. Como avances posteriores hay que señalar la concepción de Joseph Frank de spatial form (1945: 231), que caracteriza gran parte de la literatura moderna como la plasmación ante el lector de una yuxtaposición espacial; las ideas de Forster (1990: 155), Poulet (1961) y Baquero Goyanes (1989: 79-85) en relación con las estructuras narrativas dispuestas en formas geométricas espaciales; el estudio de los lugares felices o topofilia de Gaston Bachelard (1965); las relevantes aportaciones establecidas por Ricardo Gullón (1980) en su análisis del espacio novelístico; o los niveles de estructuración espacial en el texto narrativo delimitados por Zoran (1984: 316319) y Valles Calatrava (1999: 18), entre otros análisis críticos destacados.

Partiendo de los presupuestos precedentes, se puede avanzar un paso más y confirmar la identidad del espacio como un signo complejo en el seno de la ficción narrativa, al constituirse como una realidad textual y, a su vez, como un elemento ficticio que - junto al tiempo, los acontecimientos y los personajes - contribuye al nacimiento de la trama (Martínez García, 1994-95: 233-4) y siempre proporciona coherencia al universo representado. Todo ello a pesar de la transformación sufrida por su noción, su representación y sus funciones y connotaciones significativas, en virtud de la cultura propia de cada período. Cierto es que el espacio, con sus múltiples funciones y posibilidades representativas, impide que se siga hablando de dimensiones geográficas (Zumthor, 1994: 396-7), que le sirven al escritor para concretizar unos hechos, pues realmente nos encontramos ante ámbitos ficcionales que son presentados de manera singular y con vida propia (Gullón, 1980: 8). El espacio, por lo tanto, no será sólo el escenario donde se sitúan los personajes y acontecen las acciones, sino que en muchas historias se erige en protagonista o en el elemento estructurador de la trama, revistiéndose de coherentes formas y múltiples sentidos, a través de la presentación de lugares cargados de significación que construyen mundos ficcionales no sólo análogos al real, sino también maravillosos, míticos o fantásticos.

Lo que posibilita esa impronta del espacio en la ficción es su carácter de signo, configurado por diferentes dimensiones (Camarero, 1994: 
92-93; Zumthor, 1994: 347): la del espacio del discurso o significante, formado por el conjunto de signos que se conjugan en el discurso textual; la del espacio del objeto o referente, centrada en el lugar físico como objeto espacial que el escritor plasma en la obra literaria; y la dimensión del espacio de la historia o el significado, que es el que contiene la historia de la narración y el que posibilita que el escritor logre desarrollar el protagonismo y la significación simbólica de los diversos escenarios; sin dejar tampoco a un lado la olvidada dimensión del espacio de la lectura. Dado su carácter de signo, lo más justo es abarcar el espacio con todos sus valores sintácticos, semánticos y pragmáticos. Gracias a ellos se configuran sistemas sémicos en las narraciones y se organiza en cada obra un universo ficcional cuya coherencia es sostenida por un peculiar código espacial determinante en el seno del discurso.

Inicialmente, atendiendo tanto a la dimensión del espacio del discurso como a la del referente, se advierte que el espacio cumple una importante función sintáctica en las tramas novelescas. Se aprecia su valor sintáctico desde el mismo momento en que, concibiéndolo desde un punto de vista exclusivamente ontológico, se asimila a un lugar físico, en el que se ubican los personajes y los acontecimientos. Además, al situar la acción, se convierte en uno de los elementos estructurantes de la sintaxis narrativa, constituyéndose en un soporte novelesco relevante en virtud de las relaciones establecidas entre los diversos escenarios de la historia. Este elemento despliega una destacada labor estructural y determina la sintaxis narrativa a través de la organización de los diversos emplazamientos, a la vez que vincula las formas a los sentidos. Por ello, el espacio, aunque construido en la narración por medio del lenguaje, es un componente de las circunstancias que rodean al ser humano y una realidad presente en el seno de la ficción. Así pues, es necesario atender también a otro tipo de valores, concretamente los semánticos, que condicionan y matizan la interpretación de la realidad del universo ficcional.

La función semántica es tan relevante como la sintáctica y genera una gran riqueza significativa, ya sea referencial o simbólica y semiotizada. En efecto, el espacio, aparte de ser un elemento estructural y sintáctico pertinente, se convierte en el seno del discurso novelesco en un signo dotado de primordiales valores semánticos que facilitan la recreación y la interpretación del mundo ficcional. Cuando el escritor construye una narración debe tener en cuenta las capacidades significativas del espacio, si quiere alcanzar los objetivos pretendidos. Para 
lograrlo, puede utilizar variados recursos con el fin de sugerir el significado literario de la historia novelesca como, por ejemplo, la descripción o determinados signos lingüísticos espaciales.

La descripción se presenta como uno de los mecanismos que más juego proporciona al narrador novelesco, pues no desarrolla ni mucho menos una función simplemente decorativa (Garrido Domínguez, 1993: 218). Por el contrario, es un factor discursivo esencial que muestra la relevancia de la focalización ${ }^{4}$ (Ortega y Gasset, 1938: 125-133; Bal, 1985: 103-104; Garrido Domínguez, 1993: 121-150); de los sentidos (Perec, 1974: 159; Bobes Naves, 1983: 119-120; Bal, 1985: 101102, Cuesta Abad, 1989: 480, etc.), que pueden conformar los diversos ambientes ${ }^{5}$; de los objetos que otorgan contenido semántico a los diferentes escenarios; y de la perspectiva y de la distancia a la hora de construir un ámbito ficcional de actuación (Ortega, 1936: 719; Bourneuf y Ouellet, 1975: 125-126; Sánchez, 1981: 30; Bal, 1985: 67; Prado Biedma, 1999: 257-258).

El proceso de elaboración del espacio de la historia no se lograría, no obstante, sin la ayuda de otros recursos narrativos, pues su densidad semántica se deriva de su relación en el conjunto narrativo con otros códigos y unidades, como los acontecimientos, los personajes y el discurrir temporal, con los que se entremezcla y asocia. La vinculación del espacio con los citados componentes de la trama crea un contenido semántico y pone de manifiesto el significado literario y artístico de la novela. Sobresale la vinculación con los personajes, pues el espacio se convierte en un signo que remite mediante procesos metonímicos y metafóricos a la situación de los caracteres novelescos, a sus sentimientos, ideas o acciones ${ }^{6}$. De tal modo, he constatado que el

${ }^{4}$ La relación entre el focalizador y el objeto focalizado influye en la percepción e interpretación que el lector pueda hacer del espacio que se le muestra. De ahí que sea tan esencial la definición que se otorga al término focalización, de la cual se deriva su importancia, y que se basa en la distinción entre la persona que ve y la que habla. Además de todo lo mencionado, es un mecanismo que destaca también por un marcado carácter técnico derivado de su utilización en otras artes como el cine y la fotografía (Bal, 1985: 109-110).

5 La percepción inicial de un ámbito puede llevarse a cabo a través de tres sentidos: la vista, el oído y el tacto, en menor medida. Esos tres sentidos generan las diversas presentaciones de espacios en la ficción e influyen en la percepción de paisajes, formas, rumores, bullicios, etc. La conjunción de los mismos lleva al lector a adueñarse del espacio narrativo mediante sinestéticas imágenes de sonidos, sabores, tactos, perfúmenes, olores, sombras y un largo etcétera.

6 Constata Valles Calatrava (1996: 63) que «tanto los propios lugares como los ámbitos de actuación son a menudo seleccionados y presentados en una relación metonímica con el principal personaje vinculado a ellos, como una proyección de alguno de 
marco en el que se mueve el personaje es expresión de su propia figura y llega incluso, en ocasiones, a moldearle. De esta manera, el espacio adquiere mayor valor sémico por su relación con los personajes (Welleck y Warren, 1953: 265; Garrido Moraga, 1982: 189-190; M.C. Bobes, 1983: 124-125, 129; Jovita Bobes, 1998: 79), cada uno de los cuales tendrá su ámbito propio, privado y social, que se opone de forma exclusiva y excluyente a otros lugares ajenos.

Parece entonces que la gran riqueza significativa del espacio de la historia se debe, en parte, a la conversión en un ámbito vivido, experimentado y personalizado, un marco escénico que, al estar poblado por seres vinculados a sus espacios, adquiere significación y llega incluso a determinar y condicionar al personaje. Cada vez que las figuras actúan y se relacionan van dotando a los lugares de la ficción de un contenido semántico, sostenido por los cimientos de esa estructura de vínculos espaciales. Esto se consigue porque el espacio genera sentimientos y estímulos en el hombre, quien se convierte en el sujeto productor y consumidor del mismo mediante su perspectiva y sus sentidos. Se capta así el espacio con una mirada semántica, logrando que los lugares narrativos no sean neutros, sino ámbitos asociados e integrados a los personajes y acontecimientos de la historia.

Gracias a los recursos mencionados, la dimensión espacial, recreada no sólo mediante formas concretas, sino también a través de connotadores sentidos, se erige como un elemento determinante y digno de sustentar el protagonismo narrativo, sean del tipo que sean los ámbitos representados en el universo de ficción. Por esta última razón, es necesario delimitar los diversos medios que el escritor posee para crear el ámbito de actuación, es decir, el marco físico, social, psicológico, arquitectónico, antropomórfico, etc., que configura el espacio de la historia. Y sin olvidar atender a la amplitud tipológica de los espacios plasmados en las historias narrativas - como los semiotizados y simbólicos, entre otros-, aspecto en el que incidiré posteriormente.

En última instancia, no se puede pasar por alto el valor pragmático de este elemento, aspecto olvidado por gran parte de los estudiosos. La pragmática ha cobrado fuerza en el seno de la teoría de la literatura, eliminando la cerrazón estructural del texto y concibiéndolo como una

sus rasgos personales (ideas, deseos, carácter, posición social) o, más raramente y buscando el contraste, como un desajuste con ellos: palacios para nobles, arrabales para delincuentes pobres o marginados, esquinas o locales de lujo para según qué prostitutas, etc., son ejemplos que podemos encontrar frecuentemente en diversas novelas.» 
entidad no sólo sintáctica o semántica, sino también lingüística y comunicativa, implicando tanto al autor como al lector en ese proceso literario (Gullón, 1980: 42; Iser, 1987: 70, 176; Baquero Goyanes, 1989: 219; Prince, 1996: 153; Garrido Domínguez, 1996: 220). Así, el receptor de cada mensaje literario deberá actualizarlo y, mediante diversas estrategias, reorganizarlo y dotarlo de coherencia y significado ${ }^{7}$. En ese proceso desempeña una gran importancia el espacio de la lectura, pues el espacio adquiere tanta relevancia en algunas historias que los demás componentes quedan subordinados a él, convirtiéndose en la clave para descodificar el mensaje narrativo. Por ello, al analizar las tipologías espaciales no se puede centrar el estudio sólo en el espacio del significante, del objeto y de la historia, relacionados con los valores sintácticos y semánticos. Hay que atender también al espacio de la lectura que, por su carácter pragmático, ha parecido equívocamente tangencial durante mucho tiempo.

En el proceso de lectura se observa que los espacios narrativos sugieren incluso aspectos y datos no expresados explícitamente. De ahí, se deduce que la reescritura del espacio por parte del receptor es fundamental para completar la cadena comunicativa, conformada por el emisor (escritor), el mensaje (narración) y el receptor (lector). Por estas razones, es necesario reivindicar la dimensión del espacio de la lectura, importante no sólo por su actuación y significado en el seno de la ficción, sino también por las relaciones establecidas con el espacio del autor y el de la historia.

En conclusión, el espacio es un elemento de la trama que proporciona concreción y verosimilitud a la historia, pero que, además, se convierte en un signo que crea sentidos sintácticos, semánticos y pragmáticos. Posee una riqueza textual que le dota de una significación que en ocasiones, puede llegar a potenciarse más incluso que los propios, personajes que lo habitan. Por los motivos citados es muy necesario dedicar más trabajos a analizar este elemento narratológico, ya sea con

7 Al respecto establece Umberto Eco (1979: 76) que «el texto está plagado de espacios en blanco, de intersticios que hay que rellenar; quien lo emitió preveía que se los rellenaría y los dejó en blanco por dos razones. Ante todo, porque un texto es un mecanismo perezoso (o económico) que vive de la plusvalía de sentido que el destinatario introduce en él y sólo en casos de extrema pedantería, de extrema preocupación didáctica o de extrema represión el texto se complica con redundancias y especificaciones ulteriores (hasta el extremo de violar las reglas normales de conversación). En segundo lugar, porque, a medida que pasa de la función didáctica a la estética, un texto quiere dejar al lector la iniciativa interpretativa, aunque normalmente desea ser interpretado con un margen suficiente de univocidad. Un texto quiere que alguien lo ayude a funcionar.» 
un interés sistematizador o parcial, pero integrando siempre en los estudios tanto conocimientos teóricos como su consiguiente ilustración con ejemplos textuales, mediante una perspectiva sincrónica, diacrónica, comparativa o intratextual.

\section{LA DIMENSIÓN ESPACIAL EN LA NARRATIVA CONTEMPORÁNEA}

La tesis de la esencialidad del espacio como signo constructor de las tramas se puede demostrar analizando la literatura más reciente que, incluso en las obras de talante más sobrio y objetivo, la naturaleza del espacio y las relaciones instituidas entre éste y otros códigos narratológicos convierten los lugares físicos en un ámbito experimentado y coherentemente vertebrado y significativo en términos narrativos. Tras un estudio de los tres principales planos espaciales integradores de los textos de prosa de ficción -el de la localización de personajes y acontecimientos en un nivel situacional; el del diseño discursivo espacial; y el del ámbito de actuación ligado al espacio de la historia con sus hechos, seres y tiempos-, se confirma la relevancia de la dimensión espacial. Concretamente, se observa la continua construcción de un espacio humano, constituido por un sistema y entramado de ámbitos que, sometidos a una diversidad representadora, sostienen, actualizan y potencian el significado de las historias narradas.

En la narrativa contemporánea, habida cuenta de que el siglo $\mathrm{XX}$ ha sido la época en la que el espacio ha renovado la prosa de ficción de forma más profunda, se encuentran numerosas muestras que ilustran la gran impronta de la dimensión espacial en el seno del citado género literario. Se constata su lugar privilegiado en la última narrativa, así como la riqueza de su presentación y, sobre todo, el protagonismo y la gran funcionalidad y capacidad simbólica que adquiere en la literatura más reciente (Valles Calatrava, 1999: 13). Así pues, analizando los diversos modos de construir la experiencia espacial de ficción en novelas publicadas en los últimos años, se pueden extraer los pilares fundamentales, en los que se sustenta la importancia de este componente de la trama.

Previamente, para entender íntegramente el estado actual de la cuestión, no hay que olvidar que el proceso de evolución sufrido por el 
espacio comienza con la importancia que tal elemento fue adquiriendo en el arte retórico, con su inclusión dentro de la narratio del discurso y la aparición de los tópicos de cosa. Esa transformación se potencia con la relevancia con la que la descripción logra reflejar la esencialidad espacial (Garrido Domínguez, 1993: 220). Hay que tener en cuenta también que, en cada época, la presentación de este elemento estaba íntimamente unida a la situación histórica y cultural coetánea. Por ello, a lo largo de la tradición, el espacio ha sido reflejado y utilizado de manera diversa, según el ideario de cada movimiento literario (Garrido Domínguez, 1993: 228). Así, se observa cómo, si en un principio la única función de la topografía era la ornamental y embellecedora, hoy día se erige como un elemento primordial de la trama. A raíz de esto el discurso narrativo ya no se desvinculará nunca más del espacio, elemento que será imprescindible a la hora de centrar los acontecimientos en un lugar concreto.

En la actualidad, además, se ha incrementado el desarrollo de las técnicas de plasmación del espacio, al dotarlo de una mayor complejidad (Martínez García, 1994-95: 236). Por poner algún ejemplo, debemos señalar simplemente que uno de esos elementos enriquecedores de nuestra narrativa más actual es el juego de perspectivas a la hora de descubrir y conformar el mundo ficcional literario, potenciando el valor de las sensaciones sensoriales (Valles Calatrava, 1999: 25), de los objetos que caracterizan cada escenario, de la distancia desde la que se presenta (Bal, 1985: 67), de los cada vez más comunes y reveladores deícticos espaciales que los narradores utilizan muchas veces con algún sentido simbólico oculto y no simplemente como indicadores ${ }^{8}$, etc.

Se encuentran numerosos ejemplos en la narrativa actual de todos los aspectos citados. Por poner una muestra, en la novela El desorden de tu nombre, de Juan José Millás, se aprecia cómo la relevancia de ciertas sensaciones sensoriales - concretamente, gustativas y olfativas- llevan al personaje a una significativa asociăción de recuerdos: A raíz de un olor característico, el espacio en el que se encuentra le inspira antiguas sensaciones:

La enumeración de los componentes no hizo sino aumentar el rechazo de Julio, que comenzó a beberlo a sorbos con la impresión de que la mano de

8 Por ejemplo, Greimas y Courtés (1979: 247) establecen distintos espacios originados por la función deíctica de determinados elementos de la lengua que generan modelos de localización espacial. 
su madre había disuelto en él la esencia misma de toda la historia familiar; el olor evocaba algo cercano, pero oculto; se abría como una flor maligna en la superficie de la conciencia e inundaba el ambiente de vapores de cuarto de estar con mesa camilla, sillas de tapicería desflecada y televisor en blanco y negro sobre estantería vulgar de escasos volúmenes encuadernados en piel (Millás, 1988: 57).

De igual manera se plasma en muchas narraciones contemporáneas el gran valor semántico que adquieren los objetos propios del espacio de la trama. En La ignorancia, de Milan Kundera, uno de los protagonistas, emigrante durante muchos años en Dinamarca, regresa a su lugar de origen y se da cuenta, a través de los objetos que conforman el espacio natal de Praga, de que ése ya no es su verdadero hogar:

\begin{abstract}
Se habia propuesto reclamarle el cuadro y, concentrado en lo que quería decir, dejó caer la mirada sobre la muñeca del hermano y su reloj. Lo reconoció: grande, negro, pasado de moda; se quedó en su apartamento, y el hermano se lo había apropiado. No. Josef no tenía motivo alguno para indignarse. Todo había ocurrido según sus propias instrucciones; no obstante, ver su reloj en la muñeca de otro le hundió en un profundo malestar. Tuvo la impresión de reencontrar el mundo como podría hacerlo un muerto que, al cabo de veinte años, saliera de su tumba: toca tierra con el tímido paso de quien ha perdido la costumbre de caminar; apenas reconoce el mundo donde vivió, pero se topa constantemente con los restos de su vida: ve su pantalón, su corbata, en los cuerpos de los supervivientes, quienes con toda naturalidad, se los han repartido; lo ve todo y no reivindica nada: los muertos suelen ser tímidos (Kundera, 2000: 75).
\end{abstract}

Se puede deducir que el espacio pasa de ser un simple elemento decorativo a subrayar su esencialidad en la obra literaria a través de dos planos funcionales: el referencial (Garrido Domínguez, 1993: 2156) y el simbólico. La capacidad simbólica es la que, además de caracterizar a los personajes o generar semiotizaciones espaciales de gran riqueza, puede en ocasiones convertirse en el eje sobre el que se cimenta toda la acción, así como la coherencia y cohesión del material narrativo. En esta línea, no pueden olvidarse las diferentes dimensiones que configuran el signo espacial, conforme hemos analizado. En un nivel inicial, con clara función sintáctica y estructural, el espacio se muestra en su vertiente topográfica (Zoran, 1984: 316), ubicando los hechos y los personajes. En cuanto a la caracterización del espacio del referente o el objeto - utilizando los criterios (Valles Calatrava, 1999: 75) de naturaleza espacial (urbano, rural, privado, público, abierto y cerrado), de amplitud (país, ciudad, barrio, casa, habitación, rincón) y de orden taxonómico (espacios geopolíticos, posicionales, sociales 
y particulares)-, se trasluce en el análisis de narraciones recientes su presencia y riqueza textual. En esta misma dimensión situacional interesan los procedimientos mediante los que se presentan los espacios y la disposición y organización de los emplazamientos, es decir, el orden de aparición de los lugares que genera relaciones entre los anteriores y posteriores.

Pero sobresale, también a nivel situacional, su especial función que, además de localizadora, es referencial, de forma que concreta los sucesos de la historia al constituir marcos de referencia. En esta línea resalta la técnica practicada con frecuencia por muchos de los escritores contemporáneos, que ficcionalizan en el discurso novelesco espacios tomados de la realidad geográfica, partiendo de la experiencia y conocimiento personales. Así sucede, por ejemplo, con autores como Luis Mateo Díez, Caballero Bonald, Juan José Millás o, entre otros, Muñoz Molina ${ }^{9}$. Hay que tener en cuenta que ese espacio creado a partir de la imaginación del escritor, aunque en ocasiones pueda inspirarse en un lugar real, siempre conforma un nuevo mundo con vida propia que sólo tiene existencia verosímil en la obra textual, en la literatura (Castilla del Pino, 1988: 180; Goodman, 1990: 144; Albadalejo, 1992: 49-58; Garrido Domínguez, 1997: 25). De tal modo, la suma de todos los lugares plasmados en muchas de las narraciones recientes - tanto los de carácter más real como los más ficcionales-, tan detallados en ocasiones, logran convertir el espacio localizador de las historias en un verdadero protagonista más de las mismas. No es de extrañar, pues, que en muchas obras se ofrezca la imagen de un mundo ficcional con coordenadas propias y con datos pormenorizados de situación, tradiciones, población y urbanismo, que dibujan de manera íntegra y factible el marco soporte de los acontecimientos y personajes recogidos en la narración.

9 Almagro Valenzuela (2000: 206) reproduce en su estudio sobre el espacio de Plenilunio varias ideas de su autor que constatan la inspiración real en Úbeda y el poder de su imaginación creadora sobre ese ámbito: «Yo me inventé Mágina para contarme a mí mismo las experiencias de mi propia vida y la de mis mayores con un grado de intensidad y unas posibilidades de lejanía que sólo podía darme la ficción. Más que un retrato, Mágina se parece a una maqueta de ciudad, a un modelo a escala del mundo breve en el que vive sus vidas la mayor parte de la gente: una maqueta con sus estatuas que yo dispongo como si manejara meditativamente figuras de ajedrez, con sus torres en las que siempre hay un reloj, con sus espadañas, con sus calles de empedrado y de fachadas blancas y dinteles de piedra. En Mágina soy el único dueño del registro civil, como quería Balzac, y añado nuevos nombres a su vecindario o los doy de baja, según me conviene, y les asigno lugares donde vivir, costumbres, balcones exactos donde asomarse, trayectos de cada día.» 
En el segundo nivel, correspondiente al espacio del discurso o el significante, destaca el diseño espacial mediante el que se construye el ámbito de la historia a través de determinadas operaciones discursivas. Además de observar cómo se organiza el espacio narrativo a través de su disposición en el discurso, es necesario atender también a los signos linguiísticos más destacados que contribuyen a configurar el diseño espacial ${ }^{10}$, gracias a su carácter de unidad sintáctica imprescindible que dota de coherencia y cohesión a la historia novelesca. Sin embargo, en este nivel lo que resalta sobremanera es la construcción espacial mediante la descripción, un recurso que pone ya de manifiesto no sólo el valor estructural del espacio sino también su valor semántico.

En esa línea, es importante el contexto en el que aparecen las descripciones tanto geográficas y ambientales como antropomórficas. Igual de relevante es la existencia de dos formas frecuentes de descripción, la que utiliza numerosas expansiones de la denominación y la que se centra en la enumeración de los diferentes elementos que constituyen cada marco. De ahí que, además de los sentidos de la vista y el oído, tengan un gran contenido semántico los elementos cinestéti$\cos { }^{11}$, por el modo en que los personajes transmiten su propia percepción del espacio a través de sus gestos, actitudes o movimientos, delatando sus intenciones o estados de ánimo. Así se refleja en el pasaje de Rabos de lagartija, de Juan Marsé, que revela la simbólica posición del inspector frente a la casa de la pelirroja, propiciando una representación del espacio que nace del propio ámbito corporal:

... parecía tan acostumbrado a permanecer así de pie, tan quieto y con los hombros un poco encogidos y tan ajeno al trasiego de la vida en torno, a la llovizna gris o el sol implacable, que a menudo parecía alguien llegado de fuera que se hubiera extraviado en el barrio, y que no le importara su extravio ni tuviera prisa por orientarse ni por nada. Su figura alta y de movimientos sinuosos, como retardados, sugería una malformación que en

10 Por ejemplo, además de determinadas figuras estilísticas y de conectores o deícticos, son importantes también, como advierte Villanueva (1992: 172), determinados sustantivos que remiten a entidades espaciales: «Según Hamon (1973: 426) la presencia de nombres propios, históricos o geográficos, así como la 'motivation sytématique' de estos últimos y los de los personajes, actúa a modo de las citas del discurso pedagógico, es decir, como argumentos de autoridad que anclan la ficción en la objetividad externa a ella y aseguran un efecto de realidad con frecuencia acentuado. Y ello, independientemente de la correspondencia efectiva de los topónimos y antropónimos con la realidad.»

11 La semiótica narrativa habla de la importancia de los elementos cinestéticos, atendiendo a las relaciones entre los personajes mediante acciones como tocar o acercarse para escuchar (Greimas y Courtés, 1979: 154). 
realidad no tenía, una suerte de flexión muscular o de encantamiento, una disposición física a la inmovilidad (Marsé, 2000: 30-31).

En cuanto a la perspectiva y los ángulos de visión, tanto estables como dinámicos, se aprecia la importancia de la utilización de una distancia próxima o lejana según los casos, junto a la perspectiva horizontal y, en menor medida por lo común, la vertical. Lo que lleva a la conclusión de que, vinculando los diversos lugares a la mirada del personaje, se espacializa la novela y, por lo tanto, el ambiente recreado adquiere una mayor relevancia en el conjunto de la trama.

En el seno de la dimensión actuacional se sitúa el espacio del significado o de la historia, el conjunto de marcos escénicos, caracterizados mediante su vinculación con determinados personajes y acontecimientos de mayor o menor tiempo de desarrollo. Al estudiar la experiencia espacial de ficción es de justicia analizar con especial atención los diferentes ámbitos de actuación que organizan la historia, de tal modo que la trama se sustenta en los primordiales ejes espaciales de la misma. Esos grandes núcleos contienen, a su vez, múltiples subespacios y entretejen las relaciones entre los personajes, gracias a su proyección significativa. Observando una serie de novelas publicadas en los últimos años se llega a la conclusión de que ha sido inmenso el desarrollo alcanzado en los modos de representar esos universos de ficción. No sólo se asiste a la repetición de espacios estereotipados ya utilizados manidamente en épocas anteriores, sino que se encuentra una gran pluralidad de escenarios dentro de una misma narración que, ya sean referenciales o fantásticos, potencian la multiplicidad de espacios semiotizados y simbólicos, así como el juego de perspectivas.

Es latente la recurrencia de semiotizaciones (Bal, 1985: 52; Valles Calatrava, 1999: 21-3), surgidas a raíz de la dialéctica entre diversos ámbitos, como por ejemplo: el espacio estable y el dinámico, el público y el privado, el natural y el edificado, el referencial y el fantástico, el contemplado y el imaginado, el objetivo y el subjetivo, el presente y el pasado, el de la vigilia y el del sueño, el opresor y el satisfactorio, el del día y el de la noche, el del campo y el de la ciudad, el de la miniatura y el de la inmensidad, el interior y el exterior, el del afuera y el del adentro, el terrestre y el celeste, etc. Así como la también recurrente capacidad simbólica del espacio de la locura o el delirio, el paradisíaco, el del jardín, el de la isla, el acuoso, el del útero materno, el de algunos espacios geométricos como el circular o el laberíntico, y determinados escenarios limítrofes o fronterizos, así como otros ideológicos o clasistas. 
Por poner tan sólo algún ejemplo, la semiotización del espacio terrestre y el celeste presenta una gran riqueza significativa en $\mathbf{L a}$ ruina del cielo, de Luis Mateo Díez (1999b), aunque en la novela existe en cierto grado una subversión de las connotaciones propias del paraíso y el infierno. En la narración se recrea Celama, una tierra simbólica plasmada como un reino de la nada que acompaña al hombre en su destino desgraciado. Se convierte así en un espacio mítico que revela a sus habitantes la palpable realidad del infierno manifestada en la propia tierra, que es, a su vez, un fiel reflejo de las connotaciones significativas asociadas al cielo, lugar que ya no se identifica con la promesa de un paraíso. Por ello, Celama engloba las penurias y la infelicidad diaria, y despliega en todo momento un halo negativo que proyecta la sombra de la muerte y constata la existencia del infierno. Por otra parte, resalta la semiotización entre el espacio del día y de la noche presente en Días del desván, también de Luis Mateo Díez. En el relato se muestra la recreación de ese marco por medio del eje espacial arriba-abajo, localizándolo en la zona alta de la casa, pero caracterizándolo con la misma oscuridad, soledad y silencio propia de los sótanos subterráneos. Entre esos factores sobresale la oscuridad que envuelve ese lugar que, siempre opuesta a la claridad diáfana del espacio del día, potencia en un principio el miedo a consecuencia de que la noche distorsiona en su seno los límites del espacio:

El secreto del Desván estaba esparcido en la oscuridad de los rincones y, además de la inquietud y el sigilo, reforzaba el misterio en el miedo, que era como un guardián invisible que habitaba los espacios más recónditos, aquéllos de los que provenían las amenazas que susurra el silencio (Mateo Díez, 1999b: 9).

Son frecuentes también las narraciones actuales que utilizan los mencionados espacios simbólicos. Por ofrecer alguna muestra, es muy destacada la utilización de los espacios fronterizos y del espacio del útero en Rabos de lagartija de Juan Marsé (2000). Es latente el carácter fronterizo de la puerta de la casa protagonista, como espacio simbólico que une y separa a la vez (Perec, 1974: 73). Este fenómeno se debe a la existencia, muy remarcada a lo largo de la historia, de una puerta que se abre hacia el callejón y al día, y otra que se abre al barranco y a la noche. Según el adolescente protagonista, la primera le servirá para huir y ocultarse del mundo durante el día, y la segunda para escapar por la noche. Cumplen, pues, dos funciones distintas pero complementarias, al ser utilizadas siempre para resguardarse de la realidad circundante. En la novela, además, el espacio del útero se recrea 
como un lugar paralelo y similar en su significado al del hogar natal, pues en él se experimenta la protección propia del marco original. A través de la simbología del útero, la pelirroja le expone al inspector cómo el carácter de David no se puede definir como mentiroso, sino como fantasioso, provocado por las circunstancias que le han hecho crecer deprisa y en soledad, como la ausencia de la figura paterna. Sostiene la veracidad de esta aseveración mediante el hecho de que esos datos le fueron manifestados ya en el propio útero, lugar concebido por el chico como un refugio ante la hostilidad del medio exterior:

Tiene fe en algunas cosas importantes. Pero es bastante nervioso e inestable, lo admito. Un chico especial. Ya lo era antes de nacer. Su padre no lo quería, ¿sabe?, andaba por aquel entonces con otras querencias, y quizá por eso yo sentía el niño dentro de mí como... como una cosa escondida. Lo sentía como si quisiera ocultarse (Marsé, 2000: 164).

Al margen de los marcos semiotizados y simbólicos no se puede olvidar, por supuesto, los continuos espacios centrados en cuatro focos fundamentales: el camino, la ciudad, la casa y el cuerpo. El camino ${ }^{12}$ es un ámbito abierto, externo y, a su vez, un espacio por el que los personajes deambulan, cruzándose unas veces de manera indiferente e interrelacionándose en otras ocasiones, originando situaciones dotadas de una gran riqueza narrativa. En La orilla oscura, de José María Merino (1995), el viaje que realiza el protagonista de la novela, a través de los canales de la costa atlántica, se convierte en un símil de la complicada peregrinación del hombre por la vida, un camino en el que se trata de olvidar el pasado para encontrar la verdadera identidad y realidad.

La ciudad constituye un microcosmos que abarca a los personajes, los ambientes y los acontecimientos. En algunos casos su fuerza sémica es tan relevante que alcanza la total protagonía dramática (Fischer, 1998: 65; Prado Biedma, 1999: 245), actuando a veces como un ser humano ${ }^{13}$.

12 Una cuestión analizada en sus diversas variantes por estudiosos como Bourneuf y Ouellet (1975: 145), Cuesta Abad (1989: 477), Zumthor (1994: 63), Lotman (1996: 84) o Augé (1996: 110), entre otros.

13 Así sucede en La Regenta, como expone Elisabeth Sánchez (1981: 35): «Vetusta es una criatura de rutina e instinto, no inteligente; una criatura reducida a su cuerpo. El cuerpo de Vetusta sobrevive alimentándose de las energías de sus miembros individuales, succionándoles, por así decir, hacia el remolino de su espiral descendente cuyo fondo es la total inercia. A pesar del dinamismo de contrarios en lucha, la tendencia dominante del conjunto podría describirse como entropía. Esto tendería a producir una visión extremadamente pesimista si no fuera por ciertos indicios de que fuentes de energía sanas e incorruptas puedan estar disponibles para subvertir el sistema. Funcionando dentro de él y con él —no en su contra.» 
Es muy representativo el modo en que se recrea ese espacio en la novelística de Millás, partiendo de la urbe madrileña. Ese escenario pasa de ser el ámbito de localización de la historia a convertirse en un territorio propio que sostiene a los personajes, los ambientes y los acontecimientos. En Cerbero son las sombras (Millás, 1974) y El jardín vacio (Millás, 1981) se plasma una ciudad quebrada y abandonada, mientras que en el resto de las narraciones aparece reflejada con rasgos no siempre tan negativos, aunque siempre proyectando los trastornos psicológicos de los caracteres. No es mostrada la ciudad en su vertiente más cosmopolita, con multitud de paisajes y de gentes, sino que es más importante la atención concedida a determinadas zonas o barrios concretos que logran, pese a su aparente nimiedad, proyectar el espacio mental de sus habitantes.

En el seno de las historias la casa se convierte en el escenario propio de cada personaje, el lugar donde transcurre su existencia. Es un espacio recurrente en las narraciones ficcionales, ya sea presentado con más o menos detalle, atención o protagonismo. Es tan esencial su imagen porque en ella se reúnen los pensamientos junto a los recuerdos y los sueños de los seres humanos que habitan la ficción ${ }^{14}$. Se convierte en un espacio de la intimidad, en el que, sean cuales sean sus características, lo importante es la sensación que genera en el ser humano que la habita. Así, por ejemplo, en Rabos de lagartija la imagen que ofrece la casa de los protagonistas es la de una modesta vivienda situada alejada de la ciudad, en un callejón sin salida y al borde de un barranco. Pero, a pesar de la pobreza de ese escenario, la inquilina lo convierte en un ámbito protector, transformando un frágil nido en apariencia (Bachelard, 1965: 137) en un verdadero hogar:

La minúscula vivienda de realquilados está vista en un santiamén. Apenas cincuenta metros cuadrados. No hay recibidor ni vestíbulo ni antesala de nada: al cruzar el umbral ya se halla uno en el comedor, así de sopetón, frente a una mesa rectangular cubierta con un hule a cuadros, a un lado el aparador y al otro, bajo la ventana con celosías que da al callejón visto en profundidad, la máquina de coser Nogma, la mesa camilla y dos sillo-

14 De tal forma lo expresa Gaston Bachelard (1965: 35-36): «Así la casa no se vive solamente al día, al hilo de una historia, es el relato de nuestra historia. Por los sueños las diversas moradas de nuestra vida se compenetran y guardan los tesoros de los días antiguos. [...] Nos reconfortamos reviviendo recuerdos de protección. Algo cerrado debe guardar a los recuerdos dejándoles sus valores de imágenes. Los recuerdos del mundo exterior no tendrán nunca la misma tonalidad que los recuerdos de la casa. Evocando los recuerdos de la casa, sumamos valores de sueño; no somos nunca verdaderos historiadores, somos siempre un poco poetas y nuestra emoción tal vez sólo traduzca la poesía perdida». 
nes de mimbre. Se ve muy claro que lo que hoy es recibidor, comedor y sala de estar, todo a la vez, antes era salita de espera del consultorio médico: en la pared aún hay manchas descoloridas y clavos donde colgaban cuadros y diplomas (Marsé, 2000: 51).

El espacio del cuerpo se ha expuesto, desde épocas remotas, como un símil estilístico del espacio geográfico ${ }^{15}$; un modelo analógico del universo (Lotman, 1996: 84-85); un ámbito que puede ser observado, descrito y recorrido, puesto que el hombre ocupa un lugar concreto y se mueve a través de él (Gullón, 1974: 247). Un claro pasaje de $L a$ soledad era esto, de Juan José Millás (1990), revela un espectacular y diáfano símil entre el espacio del cuerpo y el espacio geográfico. Concretamente, el espacio del cuerpo será un símil de un barrio urbano, logrando reflejar mediante la comparación el penoso estado no sólo físico sino también psíquico en que se encuentra el personaje:

\begin{abstract}
Realmente, un cuerpo es como un barrio: tiene su centro comercial, sus calles principales y una periferia irregular por la que crece o muere. [...] Las uñas de mis pies son la periferia de mi barrio. Por eso están rotas y deformes. Y mis tobillos son también una zona muy débil de este barrio de carne que soy yo, donde anidan seres que han huido de alguna guerra, de alguna destrucción, de algún hambre. Y mis brazos son casas magulladas y mis ojos luces rotas, de gas. Mi cuello parece un callejón que comunica dos zonas desiertas. Mi pelo es la parte vegetal de este conjunto, pero ya hay que teñirlo para ocultar su ruina. Y, en fin, tengo también un basurero del que no quiero hablar, pero, como en todos los barrios arruinados, la porquería se va acercando al centro y ya se encuentra una con mondas de naranja en cualquier sitio. Por mi cuerpo no se puede andar de sucio que está y el Ayuntamiento no hace nada para arreglarlo (Millás, 1990: 49).
\end{abstract}

No obstante, no es la originalidad de cada una de estas tipologías espaciales la que asombra, ya que muchas de ellas se localizan ya en diferentes períodos literarios. Lo importante es la explotación conjunta de todos esos diversos modos de representar el espacio y de organizar la realidad del mundo ficcional de una manera novedosa al conce-

15 En esa línea asevera Augé (1996: 66) que «se puede atribuir este efecto mágico de la construcción espacial al hecho de que el cuerpo humano mismo es concebido como una porción de espacio, con sus fronteras, sus centros vitales, sus defensas y sus debilidades, su coraza y sus defectos. Al menos en el plano de la imaginación (pero se confunde en numerosas culturas con el de la simbólica social), el cuerpo es un espacio compuesto y jerarquizado que puede recibir una carga desde el exterior. Tenemos ejemplos de territorios pensados a imagen del cuerpo humano, pero, a la inversa, también el cuerpo humano es pensado como un territorio, en forma bastante generalizada.» 
birlo como un protagonista relevante de la novela o como el eje que posibilita el desarrollo de la narración.

Por otra parte, sin olvidar la vinculación de los diversos espacios con los personajes y el tiempo, se observan los cambios dinámicos de ámbitos de actuación marcados por las entradas o salidas de los personajes, la peculiar percepción que cada persona puede tener de un mismo espacio, sus significativas actuaciones gestuales, y la metonimia que se establece en ocasiones al identificarse algunos escenarios con el estado de ánimo de un personaje o con un concreto rasgo de su personalidad. En la novela de Lucía Etxebarría (2001), De todo lo visible y lo invisible, la casa lóbrega de la protagonista se identifica con uno de los elementos que potencian el estado depresivo de la misma. Así, tras dos intentos de suicidio ocasionados por el desengaño amoroso y vital, su mejor amigo reconoce el acierto de realizar cambios en ese hogar:

Madrid, sin embargo, volvía a conocer la primavera. Ruth contrató a una cuadrilla de pintores recomendados por Pedro - de eficiencia probada y legalidad dudosa-quienes, amén de aturdirla durante una semana con los grandes éxitos de la bachata y la cumbia en cinta-casette, pintaron las paredes en tonos albaricoque y salmón, de forma que la casa adquirió cierto aspecto festivo, como de niño endomingado. [...]

-Está mucho mejor así, dónde va a parar —opinó Pedro-. Por lo menos ahora este piso parece que tenga claridad, que esto parecía la mansión de la Familia Munster (Etxebarría, 2001: 430-431).

En cuanto a la vinculación con el tiempo se advierte que cada ámbito de actuación está marcado por un tiempo interno, además de por su relación temporal con los marcos escénicos anteriores y posteriores. Y, puesto que no es lícito dejar de matizar la importancia de la intensa interrelación entre ambos elementos, es interesante acercarse hacia el concepto de cronotopo. Los establecidos por Bajtín facilitan la localización de las conexiones espaciales y temporales en obras de nuestra tradición literaria próxima ${ }^{16}$. No obstante, para poder establecer de

16 Lo constata Mainer (2000: 175-176) al hablar de las novelas de mediados del siglo XX: «La reflexión del crítico ruso es tentadoramente sugestiva. Quien haya leído, por ejemplo, abundantes novelas de neorrealismo español de los años cincuenta reconocerá con facilidad sus cronotopos peculiares. El de un relato como El Jarama (1956), de Rafael Sánchez Ferlosio, es, por ejemplo, particularmente complejo. Es un espacio geográfico con resonancias de la guerra civil reciente (la batalla de su nombre), pero también es un espacio de encuentro social en la postguerra, muy típico de la novela de la época. Y se compone, a su vez, de dos espacio-tiempo subsidiarios y enlazados: el de la orilla del río donde los jóvenes viven su día de asueto entre bromas, coque- 
manera taxativa y general los cronotopos propios de la última prosa ficcional, incluida la gestada ya en el siglo XXI, habría que dejar pasar algo más de tiempo con el fin de gozar de una perspectiva más distanciada y coherente. A pesar de ello, es posible resaltar ya la gran impronta que despliega en la narrativa más reciente un peculiar cronotopo que dista de los que tradicionalmente han surcado la ficción narrativa. Hago referencia al configurado por un tiempo actual situado en un espacio propio de la realidad contemporánea. Se trata de un ámbito urbano, caracterizado por la celeridad de la vida moderna, cuya máxima expresión es el pequeño apartamento de ciudad que, en muchos casos, potenciará la soledad y el análisis introspectivo de la psicología de sus habitantes ${ }^{17}$.

Por otro lado, para completar la visión del signo espacial en la narrativa reciente no se puede olvidar la relevancia de la cuarta dimensión del mismo, la del espacio de la lectura. Resaltan numerosas divergencias que se producen entre el espacio de la lectura, el de la historia y el del autor, así como la posibilidad de desarrollar juegos narrativos mediante la inserción del espacio de la lectura en el seno de la propia ficción (García Peinado, 1998: 378), poniendo de relieve cómo a través de ese proceso los espacios adquieren su máximo sentido gracias a la imaginación del lector y a la labor de reinterpretación que éste lleva a cabo. En La orilla oscura, de Merino (1995), en el seno de una narración que cuestiona la identidad del ser y el grado de realidad de la existencia, hay un profundo interés por el proceso de construcción de mundos literarios. Por ello, se localizan numerosas referencias sobre la relación entre la literatura y los espacios de la vida, resaltando la mezcla de ficciones y de realidad en la mente del hombre.

En suma, se observa en muchos casos cómo la narrativa actual incide en una de las preocupaciones más trascendentales del pensamiento moderno, haciendo girar las historias en torno al individuo y al espacio

teos y apelaciones a gozar del momento, y el espacio de la venta (en una eminencia sobre el vado del río) donde los personajes más viejos viven una relación más compleja, llena de recuerdos del pasado, de transigencias estoicas y de valoraciones morales sobre la necesidad de la convivencia. Y, a la vez, aunque el tiempo parece cristalizado, en su cápsula de poco más de doce horas de un domingo de verano, el constante curso del río nos recuerda — sin necesidad de recurrir a Heráclito —que la temporalidad fluye permanentemente sobre los sueños, las acomodaciones y las miserias de los personajes.»

17 Sin ir más lejos, revisando las novelas escritas por Juan José Millás en las últimas décadas se observa la angustiosa soledad y los trastornos psicológicos, de personalidad y carácter que estos lugares angostos como cajas imprimen a sus habitantes en el seno del ámbito urbano actual, reflejado recurrentemente en la ficción. 
-urbano generalmente-, es decir, al hombre y al medio que comúnmente éste habita. Es cierto que los personajes suelen configurar el eje de las historias, pero el reflejo de su existencia no tendría el alcance deseado por los escritores de no ser por la riqueza textual proporcionada por el protagonismo del espacio en que éstos viven, es decir, del marco ambiental urbano, y en ocasiones rural, que pone de manifiesto la relevancia significativa de los pequeños mundos recreados. Así, aunque los autores persigan mostrar la psicología y la vida de sus personajes, necesitan para ello servirse del lenguaje de las relaciones espaciales para reflejar ese complejo microcosmos de experiencias entretejidas.

\section{Referencias bibliográficas}

Albaladejo, T. (1986). Semántica de la narración: la ficción realista. Madrid: Taurus.

Almagro VAlenZuela, M. ${ }^{\text {a }}$ (2000). «La realidad de la ficción: comentario del espacio en Plenilunio de A. Muñoz Molina». En Espacios literarios y artísticos, Genara Pulido y Antonio Chicharro (eds.). Jaén: Universidad.

ÁlVAREZ MÉNDEZ, N. Espacios narrativos (en prensa).

AUGÉ, M. (1996). Los no lugares. Espacios del anonimato. Barcelona: Gedisa.

BaChelard, G. (1965). La poética del espacio. México: Breviarios. FCE.

BAJTín, M. (1975). «Las formas del tiempo y del cronotopo en la novela». En

Teoría y estética de la novela. Trabajos de investigación, 237-409. Madrid: Taurus. 1989.

- (1982). Estética de la creación verbal. Siglo XXI Editores.

BAL, M. (1985). Teoría de la narrativa. Madrid: Cátedra.

BAQUERO GoYANES, M. (1975). Estructuras de la novela actual. Madrid: Castalia. 1989.

Bobes Naves, J. (1988). Las novelas 'caribes' de Francisco Ayala. Tiempo y espacio. Kassel: Reicherberger.

Bobes NAVES, M. ${ }^{\mathrm{a}}$ C. (1983). «El espacio literario en La Regenta». Revista Archivum, tomo XXXIII, 117-130.

Bourneuf, R. y Ouellet, R. (1972). La novela. Barcelona: Ariel. 1985.

CAMARERo, J. (1994). «Escritura, espacio, arquitectura: una tipología del espacio literario». Signa 3, 89-101.

Castilla del Pino, C. (1988). El discurso de la mentira. Madrid: Alianza.

Cuesta ABAD, J.M. (1989). «Los espacios de 'Fortunata'. Dialéctica espacio/refugio, espacio/prisión». En Actas del Congreso Internacional Galdós. Centenario de Fortunata y Jacinta. Madrid: Universidad Complutense. 
Eco, U. (1979). Lector in fabula. La cooperación interpretativa en el texto narrativo. Barcelona: Lumen. 1987.

Estébanez Calderón, D. (1999). Diccionario de términos literarios. Madrid: Alianza Editorial.

ETXEBARRÍA, L. (2001). De todo lo visible y lo invisible. Madrid: Espasa Calpe.

FORSTER, E. M. (1927). Aspectos de la novela. Madrid: Debate. 1990.

FrANK, J. (1945). «Spatial Form in Modern Literature». Sewanee Review LII.

GARCía PEINADO, A. (1998). Hacia una teoría general de la novela. Madrid: Arco Libros.

GARRIDO Domínguez, A. (1993). El texto narrativo. Madrid: Síntesis. - (comp.) (1997). Teorías de la ficción literaria. Madrid: Arco Libros.

Garrido Moraga, A. M. (1982). «Un ejemplo de espacio narrativo en A. Carpentier». Analecta Malacitana 5, 2, 189-200.

GoOdMAN, N. (1990). Maneras de hacer mundos. Madrid: Visor.

Greimas, A. J. y Courtés, J. (1979). Semiótica. Diccionario razonado de la teoría del lenguaje. Madrid: Gredos.

Gullón, R. (1974). «Espacios novelescos». En Teoría de la novela, Germán Gullón y Agnes Gullón (eds.), 243-265. Madrid: Taurus.

- (1980). Espacio y novela. Barcelona: Bosch.

HAMBURGER, K. (1957). La lógica de la literatura. Madrid: Visor. 1995.

ISER, W. (1987). El acto de leer. Madrid: Taurus.

KundERA, M. (2000). La ignorancia. Barcelona: Círculo de Lectores.

Lotman, I. M. (1966). La semiosfera I. Semiótica de la cultura y del texto.

Universitat de Valencia: Frónesis-Cátedra.

MARsÉ, J. (2000). Rabos de lagartija. Barcelona: Areté.

MARTÍNEz GARCía, F. (1994-95). «El poema lírico: ¿Una ficción narrativa?».

Tropelías 5-6, 207-254.

Mateo Díez, L. (1999a). Días del desván. Madrid: Alfaguara.

- (1999b). La ruina del cielo. Madrid: Ollero \& Ramos.

MerINo, J. M. (1995). La orilla oscura. Madrid: Alfaguara.

MILlÁs, J. J. (1974). Cerbero son las sombras. Madrid: Alfaguara.

- (1981). El jardín vacío. Madrid: Alfaguara.

- (1988). El desorden de tu nombre. Madrid: Alfaguara.

- (1990). La soledad era esto. Madrid: Alfaguara.

ORTEGA Y GASSET, J. (1936). «Tiempo, distancia y forma en el arte de Proust».

En El espectador, VIII, Obras Completas. Madrid: Espasa-Calpe.

- (1938). El tema de nuestro tiempo. Madrid: Espasa Calpe. 1988.

Perec, G. (1974). Espèces d'espaces. París: Galilée.

Poulet, G. (1961). Les métamorphoses du circle. París: Plon.

Prado BIEDMA, J. (1999). Análisis e interpretación de la novela. Cinco

modos de leer un texto narrtivo. Madrid: Síntesis.

SÁNCHEZ, E. (1981). «La dinámica del espacio en "La Regenta" de Clarín».

Los Cuadernos del Norte 7, 28-35.

Sullà, E. (1996). La novela. Barcelona: Crítica. 
Valles Calatrava, J. R. (1994). «Ficción y espacio narrativo. Organización y funcionamiento del espacio en La ciudad de los prodigios, de Eduardo Mendoza». En Mundos de ficción, Pozuelo, J.M. y Gómez, V. (eds.), vol II, 1527-1534. Murcia: Universidad.

- (1996). «Algunas consideraciones históricas y sistemáticas sobre el estudio del espacio narrativo». Discurso 9-10, 51-78.

- (1999). El espacio en la novela. El papel del espacio narrativo en «La ciudad de los prodigios» de Eduardo Mendoza. Almería: Universidad.

Villanueva, D. (1992). Teorías del realismo literario. Madrid: Instituto de España-Espasa Calpe.

WELleK, R. y WARREN, A. (1953). Teoría literaria. Madrid: Gredos. 1965.

Zoran, G. (1988). «Towards a Theory of Space in Narrative». Poetics Today 5, 309-335.

ZUMTHOR, P. (1994). La medida del mundo. Representación del espacio en la Edad Media. Madrid: Cátedra. 